\title{
Association between Asthma and Internet Addiction Status in Korean Adolescents
}

\author{
Chang Hoon Han ${ }^{1}$, Jae Ho Chung ${ }^{2}$, Su Jin Lee ${ }^{3}$
}

${ }^{1}$ Department of Internal Medicine, National Health Insurance Service Ilsan Hospital, Goyang, Republic of Korea; ${ }^{2}$ Department of Internal Medicine, International St. Mary's Hospital, Catholic Kwandong University College of Medicine, Incheon, Republic of Korea; ${ }^{3}$ Department of Neurology, International St. Mary's Hospital, Catholic Kwandong University College of Medicine, Incheon, Republic of Korea

Contributions: (I) Conception and design: JH Chung, SJ Lee; (II) Administrative support: CH Han; (III) Provision of study materials or patients: JH Chung, SJ Lee; (IV) Collection and assembly of data: CH Han; (V) Data analysis and interpretation: JH Chung, SJ Lee; (VI) Manuscript writing: All authors; (VII) Final approval of manuscript: All authors.

Correspondence to: Jae Ho Chung, MD, PhD. Department of Internal Medicine, International St. Mary's hospital, 22711 Simgokro $100 \mathrm{Gil} 25$ Seogu Incheon, Republic of Korea. Email: klaatu70@gmail.com; Su Jin Lee, MD. Department of Neurology, International St. Mary's hospital, 22711 Simgokro 100Gil 25 Seo-gu Incheon, Republic of Korea. Email: jiniyamyam@naver.com.

Background: Problematic Internet addiction (IA) has been shown to be associated with a variety of psychological comorbidities, but its relationship with adolescent asthma has not yet been investigated in detail.

Methods: We analyzed 18,473 adolescent patients with physician-diagnosed asthma and 205,069 nonasthmatic adolescent patients from the Korean Youth Risk Behavior Web-based Survey. Socioeconomic factors, health behavior factors, psychological factors, and IA status were assessed using the Korean Internet Addiction Proneness Scale. Multiple logistic regression analysis was performed, with adjustment for multiple cofounders, to explore the association between IA and adolescent asthma.

Results: Comparison between the adolescent asthma group and non-adolescent asthma group indicated higher rates of probable IA (13.7\% vs. $12.1 \%$, respectively, $\mathrm{P}<0.001)$, IA (4.8\% vs. $3.1 \%$, respectively, $\mathrm{P}<0.001)$, and problematic IA $(18.5 \%$ vs. $15.2 \%$, respectively, $\mathrm{P}<0.001)$ in the adolescent asthma group. After adjustment for multiple confounders, probable IA [odds ratio (OR): 1.16, 95\% confidence interval (CI): 1.08-1.26] and IA (OR: 1.07, 95\% CI: 1.02-1.12) were significantly associated with increased risk of adolescent asthma, compared to non-problematic Internet use.

Conclusions: IA is associated with an increased rate of asthma in Korean adolescents. So, IA has attracted minimal attention in relation to the treatment of asthma.

Keywords: Internet; addiction; asthma

Submitted Jul 01, 2020. Accepted for publication Dec 11, 2020.

doi: $10.21037 /$ jtd-20-2342

View this article at: http://dx.doi.org/10.21037/jtd-20-2342

\section{Introduction}

Internet addiction (IA) is a problem in certain groups of individuals, such as adolescents (1). Although the prevalence rates of problematic Internet use and IA are difficult to interpret because of differences in their definitions among studies, the prevalence of problematic Internet use (PIU) in the general population is approximately $2-8 \%$; it may reach
$20 \%$ in adolescents (2-8).

Previous prevalence and risk factors for problematic internet use among rural adolescents in Korea showed that problematic internet use was identified in $21.6 \%$ students and male gender, academic stress, early exposure to the Internet, depression was significantly associated with problematic internet use (9).

Problematic IA is associated with sleeping problems $(10,11)$, 
tobacco and alcohol use (12), overweight (13), depression, anxiety, and suicidal behavior (12). The rates of health risk behaviors, such as smoking (14), alcohol abuse, depression, and illicit drug abuse (15), are higher in adolescents with asthma than in the nonasthma adolescents. Online video game has become one of the world's most popular leisure time activities among youth, but some gaming can be problematic and potentially addictive in some adolescents (4).

However, there have been no studies to determine whether problematic IA is associated with physical health problems, such as asthma, in adolescents. There is also a need to increase knowledge regarding the distribution of adolescent asthma and its relationships with sociodemographic factors and dysfunctional Internet behavioral problems. Of particular interest are the associations between problematic IA and parameters of immune-related physical health, which have not been investigated previously. So this present study was performed to investigate the relationships of problematic IA with immune-related illnesses, such as adolescent asthma, using school-based self-reported data from a nationally representative Korean adolescent population. We present the following article in accordance with the STROBE reporting checklist (available at http://dx.doi. org/10.21037/jtd-20-2342).

\section{Methods}

\section{Study participants}

This school-based nationwide study used data of adolescents 12-18 years old from the Korea Youth Risk Behavior Web-based Survey (KYRBWS) which the survey was conducted from 1 Sep 2008 to 24 Oct 2008, 1 Sep 2009 to 20 Nov 2009, 1 September 2010 to 24 October 2010. After the survey procedures had been fully explained by well-trained interviewers and all adolescent participants (or their parents or legal guardians) had provided written informed consent, participants used self-administered questionnaires in the school's computer room to complete an online survey. The presence of asthma was defined as an answer of "Yes" to the question: "Have you been diagnosed with asthma by a doctor?" Adolescents who did not provide Korean Internet Addiction Proneness Scale for Youth-Short Form: Self Report (KS Scale) questionnaire were excluded. Ultimately, 18,473 adolescents with asthma and 205,069 non-asthmatic adolescents were included in the final analyses.

\section{Measure sociodemographic factors}

Self-administered questionnaires were used to collect data regarding age, sex, type of school [middle school, high school, or vocational school; all-boys, all-girls, or coeducation], family affluence level, residential area, residence with or away from parents, and academic achievement level, smoking, alcohol consumption, regular exercise, sexual experience, and illicit drug use, health status, stress level, and depression.

The residence area was categorized as urban or rural. Academic achievement level was assessed by asking the question: "How do you assess your academic achievement level over the past year?" Notably, parental occupations and family income are most frequently used to assess socioeconomic status. However, some adolescents are unaware of the exact income of their households, and some adolescents do not want to provide such information. Therefore, socioeconomic status assessments based on family income or parental occupation were not suitable for adolescent participants. Instead, our study socioeconomic status variables were evaluated using the family affluence scale introduced by the European Health Behavior in School-aged Children Study (16). We assessed economic status using family affluence level, because family affluence level can provide better information than traditional questions (e.g., those based on family income or parental occupation). Adolescents who answered "yes" to the following question were included in the smoking group: "Have you smoked cigarettes on more than 1 day over the past month?" (17). Adolescents who answered "yes" to the following question were included in the alcohol group: "Have you drank alcohol on more than 1 day over the past month?" (18). Regular exercise was defined by asking: "How many days of intense exercise causing an increased heart rate for at least 60 minutes have you performed over the past 7 days?" Responses were classified as "No" ( $<3$ times/week) or "Yes" ( $\geq 3$ times/week) (19). Sexual experience was categorized as "Yes" or "No" by asking: "Have you had sexual experience?" Illicit drug use was classified as "No" (never used) or "Yes" (have used) (17). Self-reported perceived stress was assessed for each adolescent by asking, "How much stress are you experiencing in your daily life?" The responses were: (I) a very high level, (II) a high level, (III) a moderate level, (IV) a low level, and (V) none and categorized as low stress (none to some stress) or high stress (moderate to very high stress); self-rated health status was categorized as healthy (fair to very good), fair, or poor (bad to very poor). The Korean version of the World Health Organization Composite International Diagnostic InterviewShort Form questionnaire (20) was used to assess depression, 
by asking: "Have you had depressed feelings for more than 2 weeks in the past year?" Responses were classified as "Yes" or "No".

\section{Problematic Internet use}

The KYRBWS used the Korean Internet Addiction Proneness Scale for Youth-Short Form: Self Report (KS Scale) questionnaire to define IA. The KS scale (21) comprises a self-administered 20-item questionnaire, which assesses cognitive-behavioral and structural pathological aspects of IA. Each item was scored using a Likert scale ( $1=$ never, 2 = sometimes, $3=$ often, $4=$ nearly always). The KS scale is composed of six factors: (I) adaptive functioning disturbance (six items, 24 points), (II) addictive automatic thought (one item, four points), (III) withdrawal (four items, 16 points), (IV) virtual interpersonal relationships (three items, 12 points), (V) deviant behavior (two items, eight points), and (VI) tolerance (four items, 16 points). Participants were divided into three groups according to Internet use, as follows: mild user ( $\leq 47$ points), potential risk for IA (48-52 points), and high risk for IA ( $\geq 53$ points). IA was defined as a total KS score $\geq 53$ or the presence of all of the following: adaptive functioning disturbance score $>17$, withdrawal score $>11$, and tolerance score $>13$. Probable IA was determined by the presence of one of the following: total KS score 48-52, adaptive functioning score $>15$, withdrawal score $>10$, or tolerance score $>12$. In this study, participants with IA and probable IA were included in the problematic Internet use group.

\section{Ethical approval and consent to participate}

This study was approved by the Institutional Review Board of the National Health Insurance Service of Ilsan Hospital (NHIMC 2020-03-029) and adhered to the tenets of the Declaration of Helsinki (as revised in 2013). The requirement for informed consent was waived by the institutional review board because of the retrospective nature of the study and because the data were de-identified within the database used for this study.

\section{Data analysis}

Basic characteristics were compared between the groups using the chi-squared test. Multiple logistic regression analyses were performed with complex sampling adjusted for age and sex (model 1); with complex sampling adjusted for model 1 plus school type, residence, living with parents, family affluence level, monthly pocket money, parental education level, academic achievement, smoking status, alcohol use, regular physical activity, sexual experience, and drug experience (model 2); and with complex sampling adjusted for model 2 plus stress, health status, happiness, and depression (model 3) to explore whether there is an association between IA and asthma. Data were analyzed using SPSS Statistics for Windows (version 21.0; SPSS Inc., Chicago, IL, USA). In all analyses, $\mathrm{P}<0.05$ was considered to indicate statistical significance.

\section{Results}

Summary statistics regarding the demographic characteristics and questionnaire data of Korean adolescents aged 12-18 years enrolled in the KYRBWS are presented in Table 1. Male sex, coeducation school type, urban living, residence away from parents, high family affluence level, high monthly pocket money, higher parental education level, and high subjective academic achievements were associated with higher rates of asthma. Smoking, alcohol intake, substance use, and sexual experience were significantly more common in the asthma group. Psychosomatic differences between participants with and without asthma were also explored. The rates of poor self-rated health, perceived stress, perceived unhappiness, and depressive mood were higher in the asthma group.

Table 2 shows a comparison of Internet usage parameters between asthma and non-asthma groups. The mean IA proneness scale total score $(31.3 \pm 11.1$ vs. $30.0 \pm 9.5$, respectively, $\mathrm{P}<0.001)$, disturbance of adaptive functioning score $(10.2 \pm 3.7$ vs. $9.9 \pm 3.3$, respectively, $\mathrm{P}<0.001)$, addictive automatic thought score $(1.4 \pm 0.8 v s .1 .3 \pm 0.7$, respectively, $\mathrm{P}<0.001)$, withdrawal score $(6.2 \pm 2.6$ vs. $5.9 \pm 2.3$, respectively, $\mathrm{P}<0.001)$, virtual interpersonal relationship score $(4.1 \pm 2.0$ vs. 3.9 \pm 1.7 , respectively, $\mathrm{P}<0.001)$, deviant behavior score (3.1 \pm 1.4 vs. $3.0 \pm 1.3$, respectively, $\mathrm{P}<0.001)$, and tolerance score $(6.4 \pm 2.9$ vs. $7.1 \pm 2.7$, respectively, $\mathrm{P}<0.001)$ were significantly higher in the asthma group than in the nonasthma group. Weekday $(125.7 \pm 103.2$ vs. $120.7 \pm 92.7$, respectively, $\mathrm{P}<0.001)$ and weekend Internet times $(191.1 \pm 131.6$ vs. $186.5 \pm 124.4$, respectively, $\mathrm{P}<0.001)$ were also significantly higher in the asthma group than in the nonasthma group. Probable IA (13.7\% vs. 12.1\%, respectively, $\mathrm{P}<0.001)$, IA (4.8\% vs. $3.1 \%$, respectively, $\mathrm{P}<0.001$ ), and problematic IA $(18.5 \%$ vs. $15.2 \%$, respectively, $\mathrm{P}<0.001)$ were significantly higher in the adolescent asthma group than in the non-asthma group. Table 3 showed association 
Table 1 General characteristic of participants according to history of asthma

\begin{tabular}{|c|c|c|c|}
\hline Variables & Asthma $(n=18,473)$ & No asthma $(n=205,069)$ & $P$ value \\
\hline Girl & $7,585(41.1)$ & $98,676(48.1)$ & \\
\hline Boy & $10,888(58.9)$ & $106,393(51.9)$ & \\
\hline Age & $14.9 \pm 1.7$ & $15.1 \pm 1.7$ & $<0.001$ \\
\hline Middle school & $10,102(54.7)$ & $104,820(51.1)$ & \\
\hline Academic high school & $6,288(34.1)$ & $74,735(36.4)$ & \\
\hline Vocational high school & 2,073 (11.2) & $25,514(12.4)$ & \\
\hline School type & & & $<0.001$ \\
\hline Coeducation & $11,775(63.7)$ & $128,927(62.9)$ & \\
\hline Residence & & & $<0.001$ \\
\hline Rural & $2,224(12.0)$ & $26,893(13.1)$ & \\
\hline Urban & $16,249(88.0)$ & $178,176(86.9)$ & \\
\hline Living & & & 0.016 \\
\hline Living without parents & $1,239(6.7)$ & $10,215(5.0)$ & \\
\hline Living with parents & $17,234(93.3)$ & $194,854(95.0)$ & \\
\hline Family affluence scale & & & $<0.001$ \\
\hline More than average & $7,664(41.5)$ & $82,650(40.3)$ & \\
\hline Farther education level & & & $<0.001$ \\
\hline Less than high school & $7,446(40.3)$ & $90,287(44.0)$ & \\
\hline More than college & $11,027(59.7)$ & $114,782(56.0)$ & \\
\hline Mother education level & & & $<0.001$ \\
\hline Less than high school & $9,381(50.8)$ & $111,851(54.5)$ & \\
\hline More than college & $9,092(49.2)$ & $93,218(45.5)$ & \\
\hline Subjective academic achievement & & & $<0.001$ \\
\hline Low & 6,893 (37.3) & $78,362(38.2)$ & \\
\hline Middle & 4,777 (25.9) & $55,671(27.1)$ & \\
\hline
\end{tabular}

Table 1(continued) 
Table 1(continued)

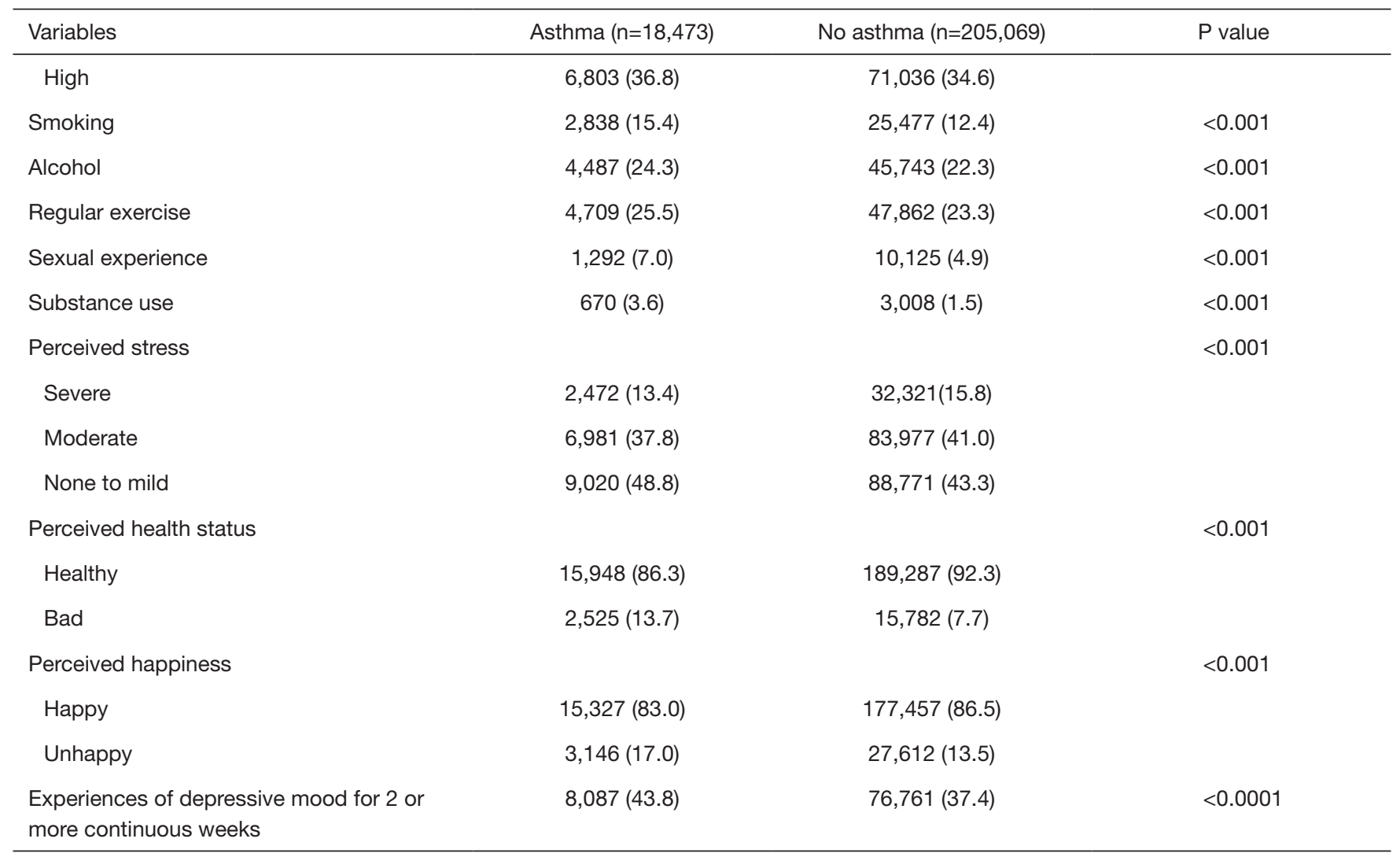

Data are presented as $\mathrm{N}$ (percent) or mean $\pm \mathrm{SD}$.

Table 2 Descriptive statistics of internet addiction

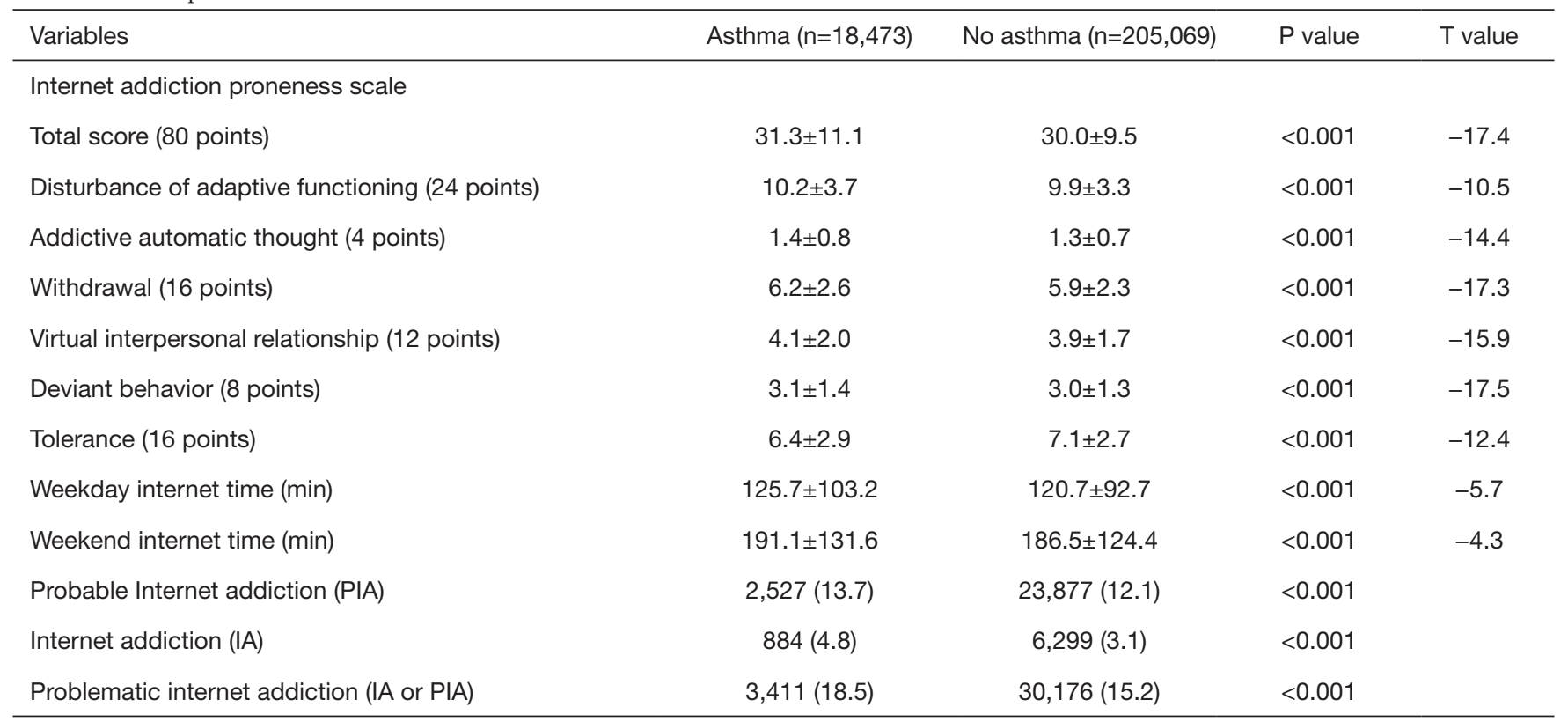

Data are presented as $\mathrm{N}$ (percent) or mean $\pm \mathrm{SD}$. 
Table 3 Association internet use status and weekday or weekend internet time

\begin{tabular}{lccccc}
\hline Variables & $\begin{array}{c}\text { Non-problematic } \\
\text { internet user }\end{array}$ & $\begin{array}{c}\text { Probable internet } \\
\text { addiction (PIA) }\end{array}$ & Internet addiction (IA) & P value & Post-hoc \\
\hline Weekday internet time (min) & $113.3 \pm 85.4$ & $151.9 \pm 105.3$ & $207.3 \pm 146.4$ & $<0.001$ & a,b,c \\
Weekend internet time (min) & $171.3 \pm 112.7$ & $250.3 \pm 141.4$ & $328.6 \pm 175.1$ & $<0.001$ & a,b,c \\
\hline
\end{tabular}

a: non-problematic internet user vs. probable internet addiction, b: probable internet addiction vs. internet addiction, c: internet addiction vs. non-problematic internet user.

Table 4 Adjusted odds ratio for asthma according to internet addiction in a young adult population

\begin{tabular}{lccr}
\hline Sleep duration & Model 1, OR $(95 \% \mathrm{Cl})$ & Model 2, OR $(95 \% \mathrm{Cl})$ & Model 3, OR $(95 \% \mathrm{Cl})$ \\
\hline Non-problematic internet user & Reference & Reference & Reference \\
Probable Internet addiction (PIA) & $1.42(1.32-1.54)$ & $1.38(1.27-1.49)$ & $1.16(1.08-1.26)$ \\
Internet addiction (IA) & $1.15(1.10-1.21)$ & $1.17(1.12-1.22)$ & $1.07(1.02-1.12)$ \\
\hline
\end{tabular}

Data are presented as odds ratios (OR) and 95\% confidence intervals (Cl). Model 1: adjusted for age, sex. Model 2: adjusted for age, sex, school type, residence, living with parents, family affluence scale, monthly pocket money, parents' education level, academic achievement, smoking status, alcohol use, regular physical activity, sexual experience, and drug experience. Model 3: adjusted for age, sex, school type, residence, living with parents, family affluence scale, monthly pocket money, parents' education level, academic achievement, smoking status, alcohol use, regular physical activity, sexual experience, drug experience, stress, health status, happiness, and depression.

internet use status and weekday or weekend internet time. Weekday $(113.3 \pm 85.4,151.9 \pm 105.3,207.3 \pm 146.4, \mathrm{P}<0.001)$ and weekend Internet times $(171.3 \pm 112.7,250.3 \pm 141.4$, $328.6 \pm 175.1$, respectively, $\mathrm{P}<0.001)$ were also significantly different among the non-problematic internet user, probable internet addiction (PIA), IA group.

The prevalence and adjusted odds ratios (ORs) for asthma according to IA status in the young adult population is presented in Table 4. After adjustment for age and sex (model 1), the OR of asthma prevalence with probable IA was 1.42 [95\% confidence interval (CI): 1.32-1.54], whereas it was 1.15 (95\% CI: 1.10-1.21) with IA, compared to non-problematic Internet use. After adjustment for model 1 plus sociodemographic factors (i.e., school type, residence, living with parents, family affluence level, monthly pocket money, parental education level, academic achievement, smoking status, alcohol use, regular physical activity, sexual experience, and drug experience) (model 2), probable IA (OR: 1.38, 95\% CI: 1.27-1.49) and IA (OR: 1.17, 95\% CI: 1.12-1.22) were significantly associated with increased risk of asthma, compared to nonproblematic Internet use. After adjustment for model 2 plus psychosomatic factors (i.e., stress, health status, happiness, and depression) (model 3), probable IA (OR: 1.16, 95\% CI: $1.08-1.26)$ and IA (OR: $1.07,95 \%$ CI: $1.02-1.12$ ) were significantly associated with increased risk of asthma, compared to non-problematic Internet use. Twenty questionnaires of the simplified Korean Internet Addiction Self-Assessment Tool (KS scale) in Table S1.

\section{Discussion}

We found that IA was associated with an increased prevalence of asthma among adolescents in South Korea. To the best of our knowledge, there have been no studies regarding links between IA and immune function; however, IA may exhibit a negative impact on immune function, mediated by the elevated levels of stress involved in problematic Internet use. Compared with our study results (asthma group: $18.5 \%$, non-asthma group: $15.2 \%$ ), prevalence of problematic internet use among rural adolescents in Korea showed 21.6\% students were problematic internet user (9).

Problematic IA may increase sympathetic nervous system activity $(22,23)$, leading to elevated levels of corticosteroids and subsequent reduced immune function (24). This pathway may support a link between IA and reduced immune function, but further studies are necessary to confirm this hypothesis. Although our study revealed that IA is associated with adolescent asthma after 
adjustment for depression, this link between problematic IA and adolescent asthma has been shown to persist beyond the effects of many other functional areas (e.g., depression and anxiety) associated with IA $(25,26)$.

Social networks, such as Facebook, may represent a new type of psychological stress that can worsen the symptoms of asthma (11). Therefore, it is advisable to consider this type of trigger when assessing exacerbation of asthma; Facebook use presumably exacerbates asthma symptoms. A previous report described a boy who experienced exacerbation of asthma symptoms upon viewing his former girlfriend's Facebook posts (27). Hyperventilation may play a substantial role in the relationship between Facebook use and exacerbation of asthma symptoms (28). Considering the high prevalence rates of asthma and problematic IA among adolescents, this type of trigger must be considered during assessment of asthma exacerbation. Data reported thus far suggest that some aspects of IA may serve as psychological triggers for illnesses, including asthma. In contrast, some studies have suggested that the positive aspect of Internet social networks may serve to increase self-esteem $(29,30)$. Józsa et al. reported that female adolescents with asthma use the Internet more frequently; this Internet use may provide social feedback to supplement their self-esteem (31).

The remarkable increase in social network use, especially among adolescents, has led health specialists to further survey the impacts of these new media on the general population and on individuals affected by chronic diseases, such as asthma. The results of the present study suggest that health care specialists should monitor the beneficial and harmful effects of Internet use among adolescents with asthma.

Notably, stress systems serve to regulate the adaptive responses of organisms to all types of stressors. Improper responsiveness may explain increased susceptibility to various disorders, including asthma. There is evidence that specific genes may be involved in stress and that inflammatory responses may influence the development of asthma (32). However, the term "psychogenic asthma" has existed for some time; it has been used to describe asthma exacerbations, which can be caused by emotional or psychological stress. Haczku et al. recently demonstrated this effect in an animal model (33). Notably, experimental data suggest that psychosocial stress may be involved in corticosteroid insensitivity, which is associated with poor response to asthma treatment. This link between mental illness and asthma has been observed in several epidemiological studies, especially with regard to anxiety and depression (34). Although this relationship between cause and effect has not yet been confirmed, advances in knowledge regarding stress-induced inflammatory mechanisms may support epidemiological findings. In the context of IA, virtual emotional stressors can cause asthma exacerbations, particularly in individuals with poor management of asthma due to concurrent depression.

Although the underlying effects of virtual stressors remain speculative, adolescent patients with asthma should undergo a thorough psychological assessment, considering virtual stressors, in clinical practice. Recent studies have shown that stressor effects are major risk factors for development of asthma-the events most closely associated with the development of asthma include divorce, marital problems, severe family illness, and serious conflict with supervisors. This hypothesis may explain why stressful life events are associated with psychological, immunological, and endocrine systems (35).

This study had some limitations. First, the cross-sectional study design did not support analysis of a potential causeand-effect relationship between IA and asthma. Further cohort studies are needed to explore the relationship between IA and asthma. Second, this study was based on web-based self-reported physician-diagnosed asthma only and not using ISAAC study question "In the past 12 (twelve) months have you had wheezing (wheezing)?" which had a good correlation with a medical diagnosis of asthma. Besides, we did not assess current asthma symptoms. Therefore, caution is necessary when interpreting our results regarding the association between adolescent asthma and problematic IA.

Despite its limitations, this study had many strengths. Because the data were gathered from a nationwide weighted sample, they presumably represent the entire South Korean adolescent population. IA has attracted minimal attention in relation to the treatment of asthma. However, further prospective studies are necessary to explore the relationship between IA and adolescent asthma. Previous study showed that asthma adolescent vulnerable bad health behaviors such as drug abuse (36) and violence (5). Our study showed that IA is associated with an increased frequency of asthma in Korean adolescents. Establishing a policy to control IA in adolescent asthma will help manage asthma control. Additional prospective studies are necessary to explore the relationship between IA and adolescent asthma.

\section{Acknowledgments}

Funding: This work was supported by National Health 
Insurance Service Ilsan Hospital grant NHIMC2020CR016.

\section{Footnote}

Reporting Checklist: The authors have completed the STROBE reporting checklist. Available at http://dx.doi. org/10.21037/jtd-20-2342

Data Sharing Statement: Available at http://dx.doi. org/10.21037/jtd-20-2342

Conflicts of Interest: All authors have completed the ICMJE uniform disclosure form (available at http://dx.doi. org/10.21037/jtd-20-2342). The authors have no conflicts of interest to declare.

Ethical Statement: The authors are accountable for all aspects of the work in ensuring that questions related to the accuracy or integrity of any part of the work are appropriately investigated and resolved. This study was approved by the Institutional Review Board of the National Health Insurance Service of Ilsan Hospital (NHIMC 202003-029) and adhered to the tenets of the Declaration of Helsinki (as revised in 2013). The requirement for informed consent was waived by the institutional review board because of the retrospective nature of the study and because the data were de-identified within the database used for this study.

Open Access Statement: This is an Open Access article distributed in accordance with the Creative Commons Attribution-NonCommercial-NoDerivs 4.0 International License (CC BY-NC-ND 4.0), which permits the noncommercial replication and distribution of the article with the strict proviso that no changes or edits are made and the original work is properly cited (including links to both the formal publication through the relevant DOI and the license). See: https://creativecommons.org/licenses/by-nc-nd/4.0/.

\section{References}

1. Block JJ. Issues for DSM-V: internet addiction. Am J Psychiatry 2008;165:306-7.

2. Christakis DA. Internet addiction: a 21st century epidemic? BMC Med 2010;8:61.

3. Chandrima RM, Kircaburun K, Kabir H, et al. Adolescent problematic internet use and parental mediation: A Bangladeshi structured interview study. Addict Behav Rep
2020;12:100288.

4. Mamun MA, Griffiths MD. The Psychosocial Impact of Extreme Gaming on Indian PUBG Gamers: the Case of PUBG (PlayerUnknown's Battlegrounds). Int J Ment Health Addict 2019. doi: 10.1007/s11469-019-00102-4.

5. Landeo-Gutierrez J, Forno E, Miller GE, et al. Exposure to Violence, Psychosocial Stress, and Asthma. Am J Respir Crit Care Med 2020;201:917-22.

6. Mamun MA, Hossain MS, Moonajilin MS, et al. Does loneliness, self-esteem and psychological distress correlate with problematic internet use? A Bangladeshi survey study. Asia Pac Psychiatry 2020;12:e12386.

7. Mamun MA, Griffiths MD. The assessment of internet addiction in Bangladesh: Why are prevalence rates so different? Asian J Psychiatr 2019;40:46-7.

8. Mamun MA, Hossain MS, Siddique AB, et al. Problematic internet use in Bangladeshi students: The role of sociodemographic factors, depression, anxiety, and stress. Asian J Psychiatr 2019;44:48-54.

9. Lee JY, Kim SY, Bae KY, et al. Prevalence and risk factors for problematic Internet use among rural adolescents in Korea. Asia Pac Psychiatry 2018;10:e12310.

10. Do YK, Shin E, Bautista MA, et al. The associations between self-reported sleep duration and adolescent health outcomes: what is the role of time spent on Internet use? Sleep Med 2013;14:195-200.

11. Mamun MAA, Griffiths MD. The association between Facebook addiction and depression: A pilot survey study among Bangladeshi students. Psychiatry Res 2019;271:628-33.

12. Durkee T, Carli V, Floderus B, et al. Pathological Internet Use and Risk-Behaviors among European Adolescents. Int J Environ Res Public Health 2016;13:294.

13. Barrense-Dias Y, Berchtold A, Akre C, et al. The relation between internet use and overweight among adolescents: a longitudinal study in Switzerland. Int J Obes (Lond) 2016;40:45-50.

14. McLeish AC, Zvolensky MJ. Asthma and cigarette smoking: a review of the empirical literature. J Asthma 2010;47:345-61.

15. Bender BG. Depression symptoms and substance abuse in adolescents with asthma. Ann Allergy Asthma Immunol 2007;99:319-24.

16. Currie C, Molcho M, Boyce W, et al. Researching health inequalities in adolescents: the development of the Health Behaviour in School-Aged Children (HBSC) family affluence scale. Soc Sci Med 2008;66:1429-36.

17. Park S, Kim Y. Prevalence, correlates, and associated 
psychological problems of substance use in Korean adolescents. BMC Public Health 2016;16:79.

18. Lim MK, Kim HJ, Yun EH, et al. Role of quit supporters and other factors associated with smoking abstinence in adolescent smokers: a prospective study on Quitline users in the Republic of Korea. Addict Behav 2012;37:342-5.

19. US Department of Health and Human Services. 2008 Physical activity guidelines for Americans: be active h, and happy! [cited 2016 Jul 20]. Available online: http:// fitprogram.ucla.edu/workfiles/Documents/Fit\%20for\%20 residents\%20curriculum/Step_5/2008_Physical_Activity_ Guidelines_for_Americans.pdf

20. Gigantesco A, Morosini P. Development, reliability and factor analysis of a self-administered questionnaire which originates from the World Health Organization's Composite International Diagnostic Interview - Short Form (CIDI-SF) for assessing mental disorders. Clin Pract Epidemiol Ment Health 2008;4:8.

21. Kim K, Ryu E, Chon MY, et al. Internet addiction in Korean adolescents and its relation to depression and suicidal ideation: a questionnaire survey. Int J Nurs Stud 2006;43:185-92.

22. Lu DW, Wang JW, Huang AC. Differentiation of Internet addiction risk level based on autonomic nervous responses: the Internet-addiction hypothesis of autonomic activity. Cyberpsychol Behav Soc Netw 2010;13:371-8.

23. Lin PC, Kuo SY, Lee PH, et al. Effects of internet addiction on heart rate variability in school-aged children. J Cardiovasc Nurs 2014;29:493-8.

24. McClelland DC, Floor E, Davidson RJ, et al. Stressed power motivation, sympathetic activation, immune function, and illness. J Human Stress 1980;6:11-9.

25. Weinstein $A$, Lejoyeux $M$. Internet addiction or excessive

Cite this article as: Han CH, Chung JH, Lee SJ. Association between Asthma and Internet Addiction Status in Korean Adolescents. J Thorac Dis 2021;13(2):968-976. doi: 10.21037/jtd20-2342 internet use. Am J Drug Alcohol Abuse 2010;36:277-83.

26. Bernardi S, Pallanti S. Internet addiction: a descriptive clinical study focusing on comorbidities and dissociative symptoms. Compr Psychiatry 2009;50:510-6.

27. D'Amato G, Liccardi G, Cecchi L, et al. Facebook: a new trigger for asthma? Lancet 2010;376:1740.

28. Ritz T, Kullowatz A, Bobb C, et al. Psychological triggers and hyperventilation symptoms in asthma. Ann Allergy Asthma Immunol 2008;100:426-32.

29. Gonzales AL, Hancock JT. Mirror, mirror on my Facebook wall: effects of exposure to Facebook on selfesteem. Cyberpsychol Behav Soc Netw 2011;14:79-83.

30. Valkenburg PM, Peter J, Schouten AP. Friend networking sites and their relationship to adolescents' well-being and social self-esteem. Cyberpsychol Behav 2006;9:584-90.

31. Józsa T, Papp A, Gonczi F, et al. Studying the health behavior of asthmatic children regarding the dimensions of media and internet usage and self-esteem. Orv Hetil 2018;159:1971-80.

32. Priftis KN, Papadimitriou A, Nicolaidou $\mathrm{P}$, et al. Dysregulation of the stress response in asthmatic children. Allergy 2009;64:18-31.

33. Haczku A, Panettieri RA Jr. Social stress and asthma: the role of corticosteroid insensitivity. J Allergy Clin Immunol 2010;125:550-8.

34. Di Marco F, Santus P, Centanni S. Anxiety and depression in asthma. Curr Opin Pulm Med 2011;17:39-44.

35. Lietzen R, Virtanen P, Kivimaki M, et al. Stressful life events and the onset of asthma. Eur Respir J 2011;37:1360-5.

36. Underner M, Perriot J, Peiffer G, et al. Asthma and heroin use. Presse Med 2017;46:660-75. 


\section{Supplementary}

Table S1 Twenty questionnaires of the simplified Korean Internet Addiction Self-assessment Tool (KS scale)

Have you ever had experiences as followed?

Never Sometimes Often always

Disturbance of adaptive functions 1 . Worse health because of internet use

2. Headache because of excessive internet use

3. Not doing what you planned because of internet use

4. Falling asleep in classes as you were tired because of internet use

5. Failing of eyesight because of internet use

6. Not able to resist using internet even you have many things to do

Positive anticipation

7. Having more self-confidence when you use internet

Withdrawal

8. Being bored and dull if you cannot use internet

9. Dithering or being nervous if you cannot use internet

10. Recurring to internet contents even when you do not use internet

11. Being angry with someone who blocks internet use

Virtual

interpersonal relationship

12. People who met in cyberspace treat me better that those who have known in real life

13. More people in cyberspace recognize me than those in real life

14. Understanding people in cyberspace more than those in real life

Deviant behaviors

15. Being tried to deceive the time of internet use

16. Spending more money because of internet use

Tolerance

17. Wanting more if you stop using internet

18. Failing to lessen time of internet use

19. Occurring a thought endlessly that you should lessen internet use

20. Others said that I use internet too much 